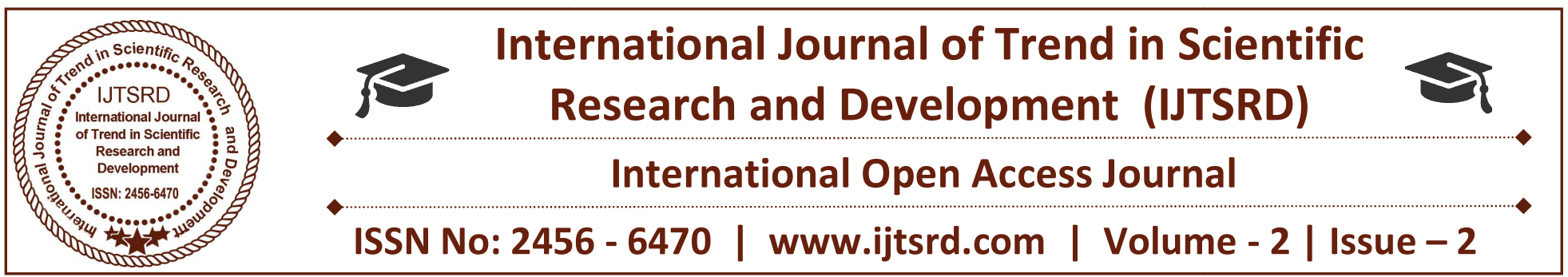

\title{
Automated Greenhouse
}

\author{
Sambasivam. $\mathbf{R}^{1}$, Gogul Ram. J. $\mathbf{K}^{2}$, Jayapal. $\mathbf{M}^{2}$, Leela Krihnan. $\mathbf{N}^{2}$, Subesh Melwin. $\mathbf{S}^{2}$ \\ ${ }^{1}$ Assistant Professor, Department of Mechatronics Engineering, SNS College of Technology, Coimbatore \\ ${ }^{2}$ UG Scholar, Department of Mechatronics Engineering, SNS College of Technology, Coimbatore
}

\section{ABSTRACT}

Proper ecological conditions are fundamental for ideal plant development, enhanced harvest yields, and ecient utilization of water and different assets, and ecient use of water and other resources. Automating the data acquisition process of the soil conditions and various climatic parameters that over run plant growth allows information to be collected at high frequency with less labour requirements. The main objective of the project is to analyze the atmospheric conditions like soil moisture, humidity, and temperature under a closed path using Arduino mega. The productivity can be increased to a greater extend using greenhouse automation. The DC pump is provided in which the relay switches on and off conditions as per the actions. This makes the DC pump to transfer water for the future process. All the atmospheric conditions are maintained at room temperature using different sensors. These automation processes can be done using various electrical components including Arduino. The main advantage of Arduino is ease of understandability and easily modifiable. We can gather the information using IOT basis. The IOT basis helps people to gather information of the current status about the updates of automation as soon as possible.

Keywords: Agriculture Machinery, Home automation

\section{Introduction}

A greenhouse is an exceptionally outlined homestead structure building to give a more controllable environment to better harvest generation, crop security, product seeding and transplanting. Also, the accessible space of area for developing yields has been altogether diminishing; following to more space of area is vigorously utilized for housing and commercial ventures as a part of this present day period. In most tropical nations, the utilization of greenhouse has been developed for cost effective farming i.e. organic products, new blossoms and vegetables generation. The effectiveness of plant creation inside greenhouse depends fundamentally on the conformity of ideal atmosphere development conditions to attain to high return at low cost, great quality and low natural burden. To attain to these objectives a few parameters, for example, light, temperature and humidity, soil moisture must be controlled ideally given certain criteria through warming, lighting, ventilation and water creation.

Persistent checking and controlling of these ecological variables gives significant data relating to the individual impacts of the different elements towards acquiring most extreme harvest creation. Greenhouse situations present remarkable difficulties to great control. Temperature changes happen quickly and fluctuate broadly relying upon sun powered radiation levels, outside temperatures and moistness levels in the greenhouse. Poor light intensity and high stickiness frequently bring about poor natural product set and quality. More exact control can decrease heating fuel and electrical expenses, expand the efficiency of labourers by empowering them to go to more important assignments, empowering directors and producers to settle on better administration choices and invest more energy dealing with the procedure. 
Today, programmed control frameworks are the standard for advanced greenhouse, with proceeded with changes as the innovation forces. Environment conditions can be kept up by these programmed control frameworks, where the framework can be worked consequently. The principle parts of any control framework are estimation controller, information preparing, information securing, information presentation and recording. In nature control framework, every parameter must be kept up incessantly inside a certain reach. Be that as it may, no such models yet exist for business greenhouse cultivation. In the agrarian area, particularly creating nations, the use of the earth control innovation is still constrained, basically on account of its high cost.

Hence, a supportable improvement of natural observing and control framework for escalated greenhouse generation is inescapable. In this thesis, we have proposed a framework that can gather the data identified with greenhouse environment and yield status and control the greenhouse consequently in view of the gathered data to foresee and follow up on circumstances for splendidly controlled climatic conditions. By thickly observing climatic conditions, this exploration has the reason for making relationship between sensors flags and reference estimations, breaking down the development, advancement of yields and the natural variables to which they are uncovered.

Moreover, control programming will give information procurement and control, genuine time graphical show, dates and time labels the data and stores it for present or later utilize. Also, by consistently observing various natural variables without a moment's delay, an agriculturist has the capacity see how development conditions are fluctuating, and respond to those progressions with a specific end goal to expand effectiveness.

\section{Methodology}

The goal of this venture is to outline a straightforward, simple to introduce, microcontrollerbased circuit to screen and record the estimations of temperature, soil dampness and daylight of the regular habitat that are constantly altered and controlled all together streamline them to accomplish greatest plant development and yield. The controller utilized is a low power, cost proficient and effortlessly accessible. It speaks with the different sensor modules continuously keeping in mind the end goal to control the light, air circulation and waste process effectively inside a nursery by impelling a cooler, fogger, dripper and lights individually as per the fundamental state of the harvests. An incorporated Liquid precious stone show (LCD) is likewise utilized for constant show of information gained from the different sensors and similar information is sent serially to a remote PC where finish information logging happens. Additionally, the utilization of effortlessly accessible segments lessens the assembling and upkeep costs. The outline is very adaptable as the product can be changed whenever. It would thus be able to be carefully fit to the particular necessities of the client.

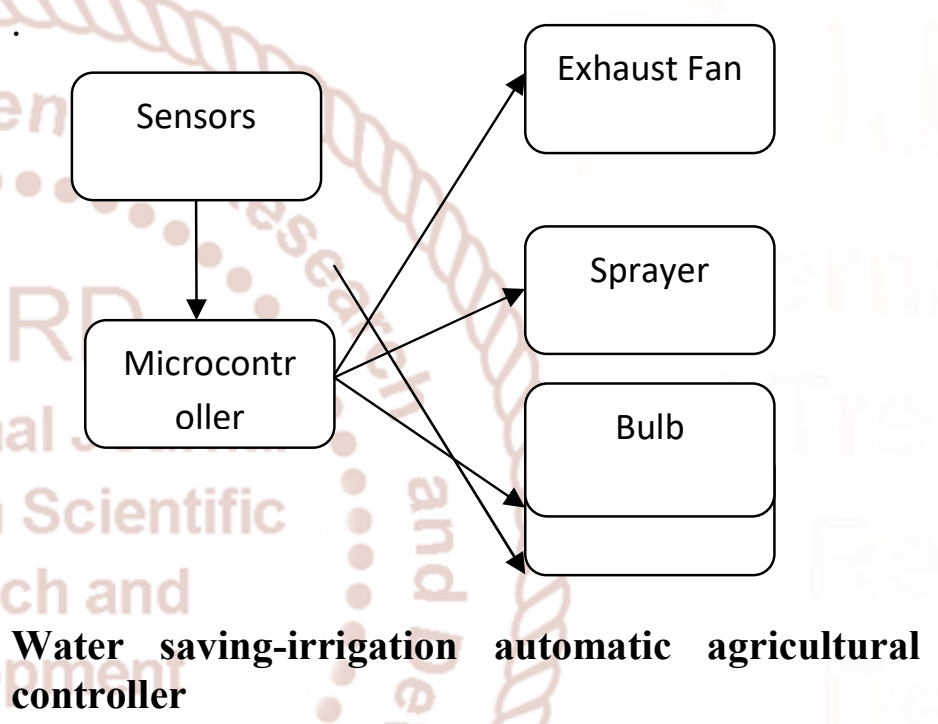

As for weather monitoring system and irrigation controller, we need to measure parameters i.e. atmospheric temperature, humidity, wind speed, wind direction, radiation, soil temperature, sunshine and rainfall etc. The key objective of this project is to report on a developed indigenous love cost time based micro-controller based irrigation scheduler who performs user defined functions and outputs commands to derive appropriate actuators (relay, solenoid valves, motor). A soil moisture sensor was modelled, simulated and tested for achieving, with low cost, accurate and reliable measurements. A low cost high performance and small temperature sensor is used, with the same PCB circuit it can measure humidity also. The tipping bucket rain gauge is used to measure rain fall. After a preset amount of precipitation falls, the lever tips, dumping the collected water and sending an electrical signal. An anemometer is a device used for measuring wind speed, and is a common weather station instrument. 
Hence current research focuses on precision agriculture, soil conservation and crop irrigation scheduling and water quantity control for increasing water use efficiency. There is a need to develop new indigenous irrigation controller to improve farm productivity and input use efficiency of water and other nutrients. This system presents the design and development of irrigation controller system built around PICI6F877A microcontroller. The system consists of micro controller, peripherals including RTC, LCD and driver circuit relay to switch on/off a motor.

\section{Automated irrigation system using a wireless sensor network and GPRS module}

An automated irrigation system was developed to optimize water use for agricultural crops. The system has a distributed wireless network of soil moisture and temperature sensors placed in the root zone of the plants. In addition, a gateway unit handles sensor information, triggers actuators and transmits data to a web application. An algorithm was developed with threshold values of temperature and soil moisture that was programmed into a microcontroller based gateway to control water quantity. The system was powered by photovoltaic panels and had a duplex communication link based on a cellular-Internet interface that allowed for data inspection and irrigation scheduling to be programmed through a web page. The automated system was tested in a sage crop field for 136 days and water savings of up to $90 \%$ compared with tradition practices of the agricultural zone were achieved.There replicas of the automated systems have been used successfully in order places for 18 month. Because of its energy autonomy and low cost, the systems has the potential to be useful in water limited geographically isolated areas.

\section{Good reasons for roof planting-green roofs and rainwater}

This presentation is expected to be an argumentative basis for a better acceptance of roof planting based on measurements made with green roofs experiments show that annual evaporation factors of $45 \%-70 \%$ of the rainfall can be achieved. When choosing ideal substrates an essential reduction of the peak run registered. Depending on the rating of rainfalls with 100,200 and 3001 reductions of peak run of as much as $52 \% 29 \%$ and $17 \%$ could begin when using efficient substrates the runoff coefficient decline with increasing watercourse. Consider watercourse of $10.0 \mathrm{~m}$ single stratum construction techniques show a $45 \%$ runoff coefficient than multi strata construction techniques.

\section{Intelligent control based fuzzy logic for automation of greenhouse irrigation system and evaluation in relation to conventional systems}

The historically extensive green roofs were designed for natural precipitation with a plant selection focusing on hardy succulents such as sedums that can survive harsh, water stressed conditions. Although this seems a convenient solution to establish and maintain a green roof system, at a much broader level this does not optimize the functions and performance of the green roof. In this paper the influence of irrigation on green roof functions and performance is presented for an extensive green roof by an extensive literature study. Green roof energy saving potential under Sri Lankan climatic conditions is significant. The average water retention of green roof substrate under different climatic zone conditions in Sri Lankan context is simulated with hypothetical twelve extensive green roof types. Results justify the artificial irrigation requirement and provide key directions to develop water balance model considering locational factors to maintain set soil moisture target.

\section{Greenhouse monitoring with wireless sensor Network}

The idea of irrigation is not new, irrigation stems asfar back as the Egyptians and probably further in unrecorded history. Even the idea of automated and drop irrigation system. Efficient the amount of water required for normal an update growth are currently available. These systems, if developed, could reduce waste of irrigation water. The irrigation controller is the "brain" of an entire irrigation system. It supervises the flow of water and fertilizer to the plant, therefore enables the farmer, or threw gardener, to obtain optimized results: A successful crop or a beautiful garden, by using an optimum amount of water and fertilizer.

\section{Drought tolerance in different vegetation types for extensive green roofs: effects of watering and diversity}

In modern greenhouses, several measurement points are required to trace down the local climate parameters indifferent parts of the big greenhouse automation system work properly. Cabling would 
make the measurement system expensive and vulnerable moreover, the cabled measurement points are difficult to relocate once they are installed. Thus a wireless sensor network (WSN) consisting of smallsize wireless sensor nodes equipped with radio and one or several sensors, is an attractive and costefficient option to build the required measurement system.

\section{Simulation of greenhouse climate monitoring and control with wireless sensor network and event- based control}

As monitoring and control of the greenhouse environment production processes. Assurance of optimal climate conditions has a direct influence on crop growth performance, but it usually increases the required equipment cost. Traditional greenhouse installations have required a green effort to connect and distribute all the sensors and data acquisition systems. These installations need many data and power wires to be distributed along the greenhouses, making the system complex and expensive. For this reason, and others such as unavailability of distributed actuators, only individual sensors are usually located in a fixed point that is selected as representative of the overall greenhouse dynamics.

\section{Multi-sensor wireless signal aggregation for environmental monitoring system via multi-bit data fusion}

This paper uses the ZigBeeCC2530 platform to various types of sensors developed for environmental monitoring systems to enhance multi-Sensor wireless signals aggregations via multi-bit decision fusion. ZigBee is a short range wireless transmission standard IEEE 802.15.4-based, formulated by the ZigBee Alliance ZigBee protocol. It is low cost, low power consumption and short-distance transmission at a transmission rate of $250 \mathrm{k}$ bps for wireless sensor networks. Its main applications include temperature, humidity and other types of data monitoring, factory automation, home automation, remote monitoring and home device control.

\section{Components}

The selection of materials involves the study of their Characteristics, advantages, availability, cost, user friendly property of components that we want to use. In our project, we select each and every components by study thoroughly about them. By proceeding like that only, we have done our selection.

\section{A. ARDUINO MEGA2560}

Arduino Mega 2560 is a microcontroller board in light of the AT mega 2560. It has 54 advanced information/yield pins (of which 14 can be utilized as PWM yields), 16 simple data sources, UARTs (equipment serial ports), a $16 \mathrm{MHz}$ precious stone oscillator, a USB association, a power jack, an ICSP header, and a reset catch. It contains everything expected to help the microcontroller, basically interface it to a PC with a USB link or power it with an $\mathrm{AC}-$ to-DC connector or battery to begin. The mega is perfect with most shields intended for the Arduino Duemilanove or Diecimila.The Arduino Mega 2560 can be controlled by means of the USB association or with an outer power supply. The power source is chosen consequently. Outer (non-USB) power can come either from an AC-to-DC connector (divider wart) or battery. The connector can be associated by stopping a $2.1 \mathrm{~mm}$ focus positive connect to the board's energy jack. Leads from a battery can be embedded in the Gnd and Vin stick headers of the POWER connector. The board can work on an outside supply of 6 To 20 volts. On the off chance that provided with under $7 \mathrm{~V}$, in any case, the $5 \mathrm{~V}$ stick may supply under five volts and the board might be insecure. On the off chance that utilizing more than $12 \mathrm{~V}$, the Voltage controller may overheat and harm the board. The prescribed range is 7 to 12 volts.

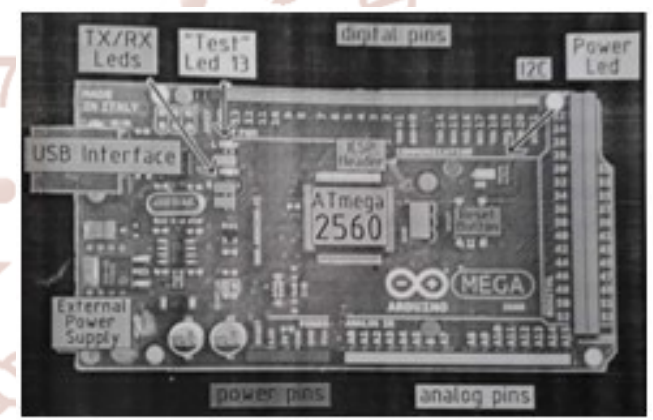

$$
\begin{gathered}
\text { FIG 1: REPRESENTATION OF ARDUINO } \\
\text { MEGA2560 }
\end{gathered}
$$

\section{B. TEMPERATURE SENSOR}

A thermistor is a sort of resistor whose protection differs with temperature. The word is a portmanteau of warm and resistor. Thermistor are broadly utilized as in surge current limiters, temperature sensors, selfresetting over current Protectors, and automatic warming components. Thermistors contrast from protection temperature locators. (RTD) in that the material utilized as a part of a thermistor is by and large an earthenware or polymer, while RTDs utilize 
unadulterated metals. The temperature reaction is likewise unique. RTDs are Useful over bigger temperature ranges, while thermistors normally accomplish a Higher exactness inside a restricted temperature run (more often than not $90 \mathrm{C}$ to $130 \mathrm{C}$ ).

\section{FIG 2 TEMPERATURE SENSOR}

\section{SOIL MOISTURE SENSOR}

Soil moisture sensors measure the water content I soil. A Soil moisture probe is made up of multiple soil moisture sensors. One common type of soil moisture sensors in commercial use is a frequency domain sensor such as a capacitance sensor. Another sensor, the neuron moisture gauge, utilize the moderator properties of water for neurons cheaper sensors often for home se are based on two electrodes measuring the resistance of the soil. Sometimes the simply consists of bare (galvanized) wires, but there are also probes with wire embedded in gypsum.
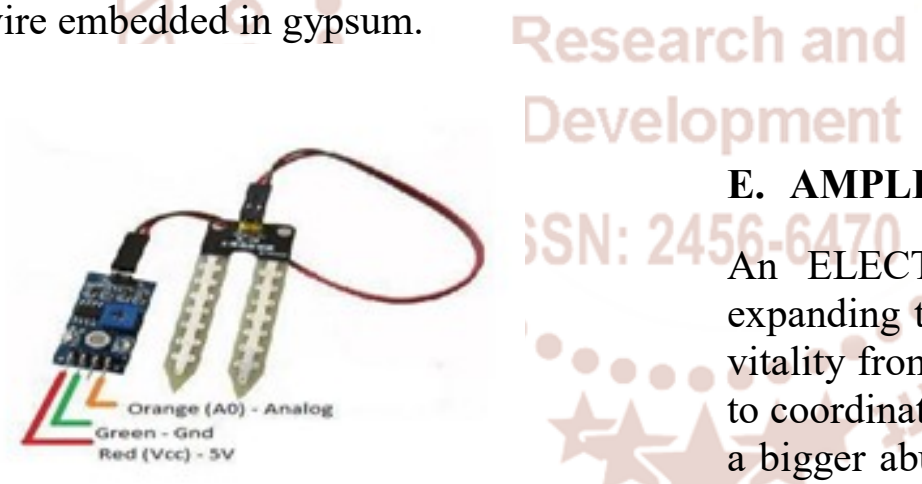

quantifies both air temperature and dampness. Relative dampness, communicated as a percent, is the proportion of real dampness noticeable all around to the most elevated measure of dampness air at that temperature can hold. The hotter the air is, the more dampness it can hold, so relative moistness changes with vacillations in temperature. The most widely recognized kind of HUMIDITY SENSOR utilizes what is called "capacitive estimation". This framework depends on electrical capacitance, or the capacity of two close-by electrical conduits to make an electrical field between them. The sensor itself is made out of two metal plates with a non-conductive polymer film between them. The film gathers dampness from the air, and the dampness causes minute changes in the voltage between the two plates. The adjustments in voltage are changed over into computerized readings demonstrating the measure of dampness noticeable all around.
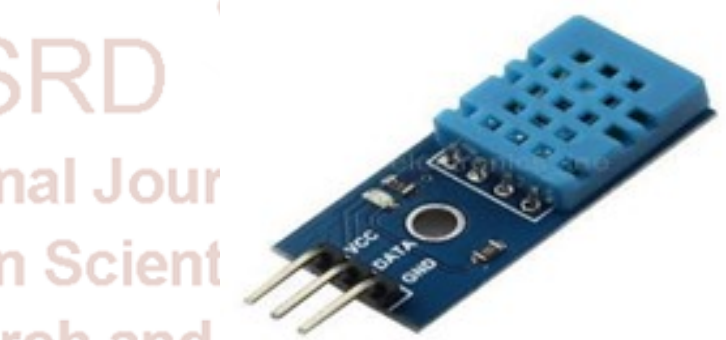

FIG 4 HUMIDITY SENSOR

\section{E. AMPLIFER}

An ELECTRONIC AMPLIFIER is a gadget for expanding the energy of a flag. It does this by taking vitality from a power supply and controlling the yield to coordinate the information flag shape however with a bigger abundancy. In this sense, an enhancer might be considered as tweaking the yield of the power supply. Here we utilize modifying enhancer as a pick up speaker. We can change the pick up by altering the estimation of criticism protection value.As the open circle DC pick up of an operational speaker is to a great degree high we can stand to lose some of this pick up by interfacing a reasonable resister over the intensifier from the yield terminal back to the modifying input terminal to both diminish and control the general pick up of the enhancer. This at that point delivers and impact referred to generally as Negative Feedback, and in this manner creates an extremely stable Operational Amplifier framework.

Negative Feedback is the way toward "sustaining back" a portion of the yield motion back to the 
information, yet to influence the criticism to negative we should encourage it back to the "Negative info" terminal utilizing an outer Feedback Resistor called Rf. This criticism association between the yield and the rearranging input terminal delivers a shut circle circuit to the intensifier bringing about the pickup of the speaker now being called its Closed-circle Gain.

\section{F. LDR SENSOR:}

Light Dependent Resistor (LDR) otherwise called photoconductor or photocell, is a gadget which has a protection which fluctuates as indicated by the measure of light falling on its surface. Since LDR is to a great degree touchy in noticeable light range, it is appropriate for the proposed application.

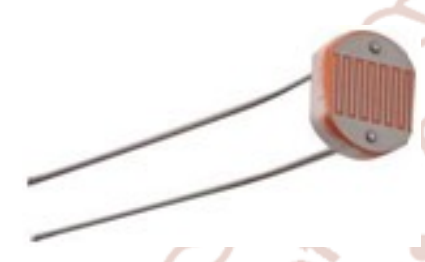

FIG 6: LIGHT DEPENDENT RESISTOR

\section{Features of the light sensor:}

1. The Light Dependent Resistor (LDR) is made using the semiconductor Cadmium Sulphide (CdS).

2. The light falling on the brown zigzag lines on the sensor causes the resistance of the device to fall. This is known as a negative co-efficient. There are some LDRs that work in the opposite way i.e. their resistance increases with light (called positive coefficient).

3. The resistance of the LDR decreases as the intensity of the light falling on it increases. Incident photons drive electrons from the valence band into the conduction band.

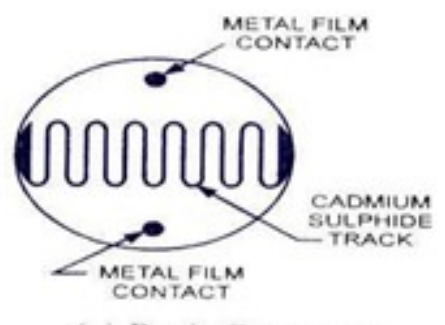

(a) Basic Structure

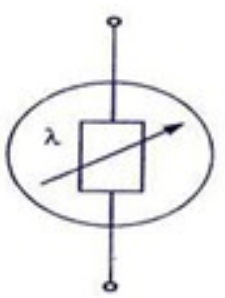

(b) Symbol
$L D R$

Fig 6.1 Structure of a Light Dependent Resistor, showing Cadmium Sulphide track and an atom to illustrate electrons in the valence and conduction bands

\section{G. RELAY}

A relay is an electrically worked switch. Current coursing through the curl of the hand-off makes an attractive field which pulls in a lever and changes the switch contacts. The loop current can be on or off so transfers have two switch positions and they are twofold toss (changeover) switches. Transfers enable one circuit to switch a moment circuit which can be totally separate from the first. For instance a low voltage battery circuit can utilize a transfer to switch a $230 \mathrm{~V}$ AC mains circuit. There is no electrical association inside the hand-off between the two circuits; the connection is attractive and mechanical. The curl of a hand-off passes a generally huge current, normally $30 \mathrm{~mA}$ for a $12 \mathrm{~V}$ hand-off, yet it can be as much as $100 \mathrm{~mA}$ for transfers intended to work from bring down voltages. Most ICs (chips) can't give this current and a transistor is generally used to open up the little IC current to the bigger esteem required for the hand-off curl. The greatest yield current for the mainstream 555 clock IC is $200 \mathrm{~mA}$ so these gadgets can supply hand-off curls straightforwardly without intensification.

\section{ch and}
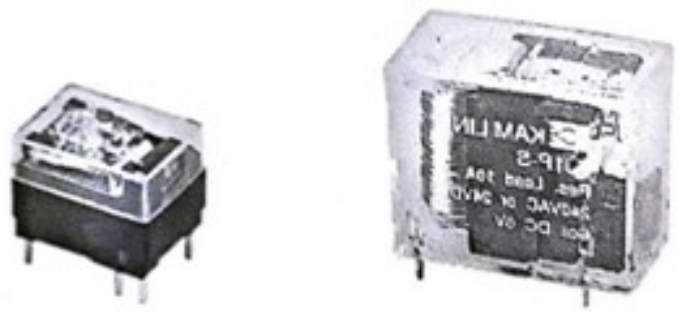

FIG 5.2.7 (A). RELAY

Relay are generally SPDT or DPDT however they can have numerous more arrangements of switch contacts, for instance transfers with 4 sets of changeover contacts are promptly accessible. Most transfers are intended for PCB mounting yet you can weld wires specifically to the pins giving you take care to abstain from liquefying the plastic instance of the hand-off. The vivified picture demonstrates a working hand-off with its curl and switch contacts. You can see a lever on the left being pulled in by attraction when the loop is exchanged on. This lever moves the switch contacts. Fig. 3.8. Shows there is one arrangement of contacts (SPDT) in the frontal area and another behind them, making the transfer 


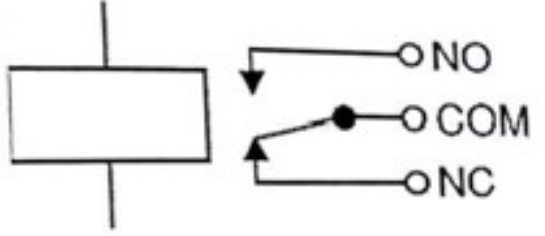

FIG. 5.2.7 (B) RELAY DIAGRAM

The relay's switch connections are usually labeled $\mathrm{COM}, \mathrm{NC}$ and $\mathrm{NO}$ :

$\mathrm{COM}=$ Common, always connect to this, it is the moving part of the switch.

$>\quad \mathrm{NC}=$ Normally Closed, $\mathrm{COM}$ is connected to this when the relay coil is off.

$\mathrm{NO}=$ Normally Open, $\mathrm{COM}$ is connected to this when the relay coil is on.

\section{H. LIQUID CRYSTAL DISPLAY}

A liquid crystal display (LCD) is a thin, level show gadget made up of any number of shading or monochrome pixels exhibited before a light source or reflector. Every pixel comprises of a section of fluid precious stone atoms suspended between two straightforward anodes, and two polarizing channels, the tomahawks of extremity of which are opposite to each other. Without the fluid gems between them, light going through one would be obstructed by the other. The fluid precious stone bends the polarization of light entering one channel to enable it to go through the other. Numerous microcontroller gadgets utilize 'shrewd LCD' presentations to yield visual data. LCD shows outlined around Hitachi's LCD HD44780 module, are modest, simple to utilize, and it is even conceivable to deliver a readout utilizing the $8 \times 80$ pixels of the show. They have a standard ASCII set of characters and scientific images. For a 8-bit information transport, the show requires a $+5 \mathrm{~V}$ supply in addition to $11 \mathrm{I} / \mathrm{O}$ lines. For a 4-bit information transport it just requires the supply lines in addition to seven additional lines. At the point when the LCD show isn't empowered, information lines are tri-state and they don't meddle with the activity of the microcontroller. Information can be put at any area on the LCD. For $16 \times 2 \mathrm{LCD}$, the address areas are:

\begin{tabular}{|lllllllll|}
\hline First line & 80 & 81 & 82 & 83 & 84 & 85 & 86 & through 85 \\
Secoud line & C0 & Cl & C2 & C3 & C4 & C5 & C6 & through \\
\hline
\end{tabular}

Fig 5.2.8 Address locations for a $2 \times 16$ line LCD

\section{CONCLUSION}

The literature reviews helped in understanding the difficulties experienced in the previous work of the authors. The ideologies which are similar to our proposed system are studied carefully and the merits, demerits are taken care. However the general procedure for taking care of sensors and handling the electrical appliances will.

\section{Acknowledgment}

We take immense pleasure in expressing our humble note of gratitude to our project guide Mr.R.Sambasivam Assistant Professor Department of Mechatronics Engineering for his remarkable guidance in doing our project.

\section{REFERENCE}

1. Dhumal, Y. R., and J. S. Chitode. "Green house automation using Zigbee and smart phone." International Journal of Advanced Research in Computer Science and SoftwareEngineering Research Paper 3.5 (2013).

2. Sung, Wen-Tsai, and Ming-Han Tsai. "Multisensor tlf wireless signal aggregation for environmental monitoring system via multi-bit data fusion." Appl. Math. Inf. Sci 5.3 (2011): 589603.

3. Gutiérrez, Joaquín, et al. "Automated irrigation system using a wireless sensor network and GPRS module." IEEE transactions on instrumentation and measurement 63.1 (2014): 166-176.

4. Durhman, Angela Keri. "Evaluation of crassulacean species for extensive green roof applications." (1984): 2064-2064.

5. Bhosale, Pranita A., and V. V. Dixit. "Water saving-irrigation automatic agricultural controller." International Journal of Scientific \& Technology Research 1.11 (2012): 118-123.

6. Nagase, Ayako, and Nigel Dunnett. "Drought tolerance in different vegetation types for extensive green roofs: effects of watering and diversity." Landscape and urbanplanning 97.4 (2010): 318-327.

7. Dunnett, Nigel, and Noel Kingsbury. Planting green roofs and living walls. Portland, OR: Timber Press, 2008.

8. Moon, H. J., K. A. An, and S. W. Han. "EnergySaving Effects of Green Roof in Existing 
Buildings with Low Insulation Levels." ASim2014Proceedings, International IBPSA Building Simulation Conference. 2014.

9. Kolb, Walter. "Good reasons for roof plantinggreen roofs and rainwater." InternationalConference on Urban Horticulture 643. 2002.

10. Chavan, C. H., and Mr PV Karande. "Wireless monitoring of soil moisture, temperature humidity using zigbee in agriculture." International Journal of Engineering Trends andTechnology (IJETT)Volume 11 (2014).

11. Pawlowski, Andrzej, et al. "Simulation of greenhouse climate monitoring and control with wireless sensor network and event-based control." Sensors 9.1 (2009): 232-252.

12. Heendeniya, H. K. C. B., R. M. M. Ruwanthika, and AG Buddhika P. Jayasekara. "Potential for improving green roof performance through artificial irrigation." MoratuwaEngineering Research Conference (MERCon), 2016. IEEE, 2016.

13. Ahonen, Teemu, Reino Virrankoski, and Mohammed Elmusrati. "Greenhouse monitoring with wireless sensor network." Mechtronic and Embedded Systems and Applications, 2008.MESA 2008. IEEE/ASME International Conference on. IEEE, 2008.

14. Kia, P. Javadi, et al. "Intelligent control based fuzzy logic for automation of greenhouse irrigation system and evaluation in relation to conventional systems." World AppliedSciences Journal6.1 (2009): 16-23.

15. Mandow, Anthony, et al. "The autonomous mobile robot AURORA for greenhouse peration." IEEE Robotics \& Automation Magazine 3.4 (1996): 18-28. 